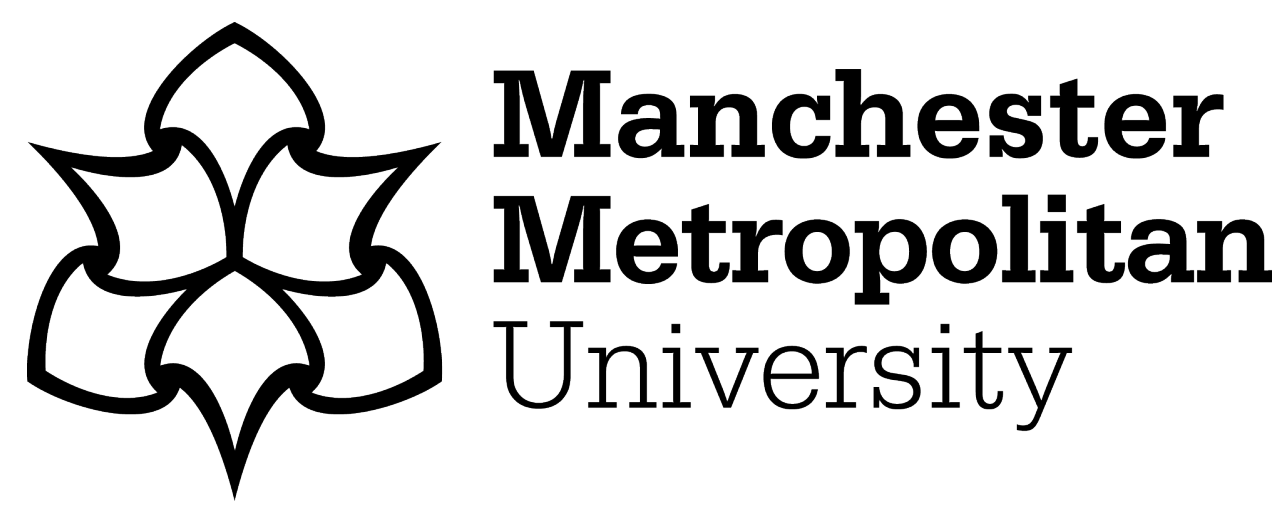

Bussu, Sonia ORCID logoORCID: https://orcid.org/0000-0003-0360-7070, Lalani, Mirza, Pattison, Stephen and Marshall, Martin (2021) Engaging with care: ethical issues in Participatory Research. Qualitative Research, 21 (5). pp. 667-685. ISSN 1468-7941

Downloaded from: https://e-space.mmu.ac.uk/624934/

Version: Accepted Version

Publisher: SAGE Publications

DOI: https://doi.org/10.1177/1468794120904883

Please cite the published version 


\title{
Engaging with care: ethical issues in Participatory Research
}

\author{
Sonia Bussu, Mirza Lalani, Stephen Pattison and Martin Marshall
}

Abstract

This paper contributes to the literature on ethics in Participatory Research (PR) by looking at the Researcher-in-Residence model and its application within health services research in three East London boroughs. The Researcher-in-Residence is embedded in the organisation to enable knowledge mobilisation and knowledge coproduction. Whereas negotiation of different types of expertise to coproduce evidence might raise issues of power differentials, the embedded nature of the role also requires careful negotiating of relationships. As the researcher is immersed in the context under evaluation, the boundaries between the researcher and the participants' everyday working life can become blurred. The paper explores these ethical issues and suggests that, whereas the requirements of ethics committees, based on an ethics of principle, at times fail to offer appropriate guidelines for this methodological approach, an ethics of care based on relationships can offer a complementary framework to address some of the thorny challenges that emerge from everyday practice in $P R$.

\section{Introduction}

The past decade has witnessed growing popularity of participatory approaches to research (Bergold and Stefan 2012; Boivin et al. 2014; Flicker et al. 2007). Participatory Research (PR) entails doing research with rather than on participants. From a functionalist perspective, it promises opportunities for more relevant evidence through ongoing collaboration among professionals, academics, and community members involved in the research process, helping to bridge the gap between academia and the real world, fostering engagement with the findings, and increasing commitment to using evidence for policy change (Marshall 2014; Vindrola-Padros et al. 2017). From a democratic perspective, the involvement of new voices and interests in framing problems and defining issues can help challenge beliefs that might disadvantage some social groups (Banks et al. 2013). The focus on solving practical problems by linking theory and action through reflective cycles, which characterises much PR, has the potential to produce social change, as well personal development and learning for those involved. However, definitions and interpretations of what PR means vary and different participatory studies entail different degrees of participation. In some, involvement may be limited to the data generation phase, while participants are excluded from decisions over design and dissemination processes (see Mannay et al. 2016 and 2018; Staples et al. 2019). While some studies engender forms of meaningful participation, others are accused of simply "ticking boxes and missing the point" (Batsleer 2008: 141; see also Mannay et al. 2018).

PR poses several ethical challenges (Wilson et al. 2018), which can at times conflict with the principalist ethical approaches characteristically adopted by Research Ethics Committees (REC), particularly within healthcare research (Beauchamp and Childress 2001). Doing research with, rather than on, participants problematises traditional ethics requirements of informed consent, anonymity and confidentiality. Furthermore, new ethical problems emerge from everyday practice, where decisions that might have 
profound ethical ramifications need to be made quickly, as examined in the next sections (Guillemin and Gillam 2004).

This paper contributes to the literature on the ethical issues raised by PR (Mannay 2015; Manney et al. 2017; Lomax 2015, 2018) and argues that feminist critical theory (Noddings 1984) can provide a more appropriate ethical framework for PR than an ethics of principle. We propose an ethics of care rooted in "affective aspiration lodged in relationship rather than a pursuit of some principle, such as fairness or virtue" (Preissle 2012: 518). Ethics of care starts from the premise that humans are inherently relational (Noddings 1984); it is both a "feminine" ethic and a human ethic, emphasising the importance of everyone having a voice and being listened to. Ethics becomes a pragmatic endeavour to look into problematic social conditions and improve them (Dewey, [1930] 1984). These perspectives are highly significant for the Researcher-in-Residence model of PR presented here, which places the researcher as a member of the delivery team (Marshall et al. 2014) to enable knowledge mobilisation (Holmes et al. 2017) and knowledge coproduction (Vindrola-Padros et al. 2018).

The paper consists of five main sections. The next two sections describe the Researcher-in-Residence model and places it within the family of PR, reflecting on some of the ethical issues raised by participatory approaches. We build on recent literature on the ethics of PR and reflect on the merits of an ethics of care vis-à-vis an ethics of principle to support ethical PR. The following section presents two participatory evaluations of integrated care that were carried out in East London in 2017/ 2018, reflecting on issues and problems about ethics arising from our empirical application of the in-residence model. We distinguish between issues of procedural and everyday ethics, or ethics in practice (Guillemin and Gillam 2004), and argue that these problems risk remaining unresolved within the ethical processes and assumptions of ethics committees and protocols. Instead, an ethics of care echoes and validates the situations we experienced on the ground. Finally, the conclusion provides suggestions for ethics committees to ensure they are more appropriately supportive of PR.

\section{The Researcher-in-residence model}

PR has its origin in Lewin's (1946) action research and was initially linked to organisational development with a strong emphasis on utilitarian problem-solving and a focus on changing practice within an organisation. ${ }^{1}$ Epistemologically, action research is concerned with changing the world as well as describing and explaining it (Reason and Bradbury 2006), and research is expected to make a useful contribution to the organisation (Coghlan and Brannick 2010). Researchers and participants' experiences and opinions inform an iterative cycle of (a) planning, (b) taking action and (c) evaluating the action, leading to further planning and so on (McNiff and Whitehead 2011). Knowledge is co-produced and the researcher helps mobilise different types of expertise, by being a "facilitator, interlocutor, capacity developer and advocate" (Genat 2009: 114).

Maurer and Githens (2010) distinguish between Conventional, Dialogic and Critical action research. Within conventional action research, the researcher is perceived as an expert; $s($ he) enters a consultative relationship to respond to organisational needs, seeking solutions to agreed goals. Dialogic action research emphasises critical engagement between the researcher and the participants to 
question dominant norms. Critical action research, often referred to as participatory action research, is fundamentally political and aims to empower excluded groups (Macintosh et al. 2007; Githens 2015). ${ }^{2}$

The combination of co-production of new knowledge and mobilisation of established knowledge is central to the in-residence model, one approach to dialogical action research and the focus of this paper, in which the researcher supports ongoing learning (Marshall et al. 2014). The model has three defining characteristics, whereby the researcher:

- is embedded within the organisation studied, rather than primarily in an academic institution;

- brings a new body of expertise to the team, e.g. knowledge of established research evidence, interpretation of relevant theories to guide change;

- brings an ability to negotiate and build upon different forms of knowledge and expertise.

The model to date has been mainly implemented within health settings on a wide range of quantitative and qualitative evaluations of health services (Vindrola-Padros et al. 2017). It was developed in response to two main problems with health services research. First, there is a corpus of important academic evidence that is often ignored after publication and organisations often find themselves trapped in reinventing-the-wheel cycles, as they do not always have access to previous learning. An academic expert sitting within an organisation can help translate previous evidence into lessons that can be communicated clearly to professionals in ways relevant to their needs. Second, academic research does not always directly address organisational needs and priorities. Academic and professional experts developing research questions and interpreting findings together can create opportunities to coproduce more relevant knowledge to influence policy development. Thus, the in-residence model contributes to the growing knowledge-to-action movement (Holmes et al. 2017). An embedded researcher within the organisation can also help generate research capacity-building, through transfer of knowledge and skills (Vindrola-Padros et al. 2018). For instance, researchers can hold up a mirror to support programme development. One objective of our study was to help participants strengthen their own monitoring capacity for progress; we developed a maturity matrix with some of our participants, and this was used by integrated care teams locally to assess the development of their partnership.

Similarly, to other participatory approaches, the Researcher-in-Residence also has an ethnographic dimension. Immersed in a setting, much of the evidence is collected by watching behaviour, listening to conversations, and asking questions (Murphy and Dingwall 2011). Ethical dilemmas arise from the researcher's embeddedness, around anonymity and confidentiality (Murphy and Dingwall 2011). However, within ethnography the authorial voice is the researcher's own (Josselson 1996), with the problematic power implications that this may entail; for instance, it might be difficult for the participants to defend alternative definitions of their situation. Within PR, there exist different voices and definitions of the same situation, each embedded with different power relations; negotiating different understandings can create novel ethical dilemmas. That said, several of the issues raised here will be relevant for non-participatory qualitative research. 


\section{Doing ethical Participatory Research}

Traditionally four ethical principles based on the Helsinki declaration (WHO 2001) inform the ethics of all research involving human subjects:

- Respect for autonomy, or the decision-making capacities of participants by enabling them to make reasoned, informed choices;

- Beneficence, or considering the balance of benefits of participating in the research against risks and costs;

- Non-maleficence, or avoiding causation of harm;

- Justice, or ensuring the benefits of the research are equally distributed across all groups in society.

These normative principles, which inform institutional research ethical guidelines and procedures, assume that moral judgements are fundamentally rational, in the sense that a reasonable and autonomous individual agent should be able to reconstruct their reasons for acting (for a critique of normative principles see Hampshire 1978). Principalist ethics guidelines were created with positivistic research designs in mind (Boser 2006), but this biomedical framing might be inadequate for the emergent and context-dependent nature of PR, and more broadly qualitative research (Guillemin and Gillam 2004). The focus on individual subjects may run the risk of disregarding the collectiveness of PR, whereby participants are considered both as individuals and a community (Flicker et al. 2007).

Contemporary ethics has been dominated by this focus on supposedly universal, objective, and logical reasoning. Feminist ethicists (Held 1987) and feminist epistemologists (Moody-Adams 1997) reject this view of ethical frameworks as either universal or objective. Noddings calls it "the language of the father" and proposes introducing into ethics the "mother's voice" (cited in Preissle 2012). Gilligan (1982) identifies two different approaches to addressing moral dilemmas: the first is impersonal, resorting to logic and law; the seconds is personal, using communication and human relations. Without denying the relevance of universal principles like justice, our experience as Researchers-in-Residence highlighted how an ethics rooted in the relationship of caring, and being cared for, can be of greater use when the research process entails reflexive and overt exploration of power and interests (Gilligan 1982; Noddings 1988; Maiter et al. 2008). Ethics committees do not normally require discussion of ethical aspects inherent to PR such as examination of issues associated with perceived bias and coercion. These can relate to what the researcher sees and asks, what participants think the researcher wants to hear, and what participants choose to emphasise, include or exclude (Holian and Coghlan 2013). Renold et al. (2008: 429) astutely observe how "ethics committees rarely assist the researcher's negotiations of 'ethics-in-practice' - that is, the actual ethical conduct of the research project". ${ }^{3}$

Discussing the ethical implications of her research with teenagers, Allen (2009) observes how ethics committees' attempts to reduce risk curbed her research participants' creative agency. Scholars have developed creative solutions to navigate these complexities (see Victoria Edwards' "case of ethics" ${ }^{4}$ ) but often the narrow frame and timelines of institutional ethics risks undermining "a methodology [such as PR] seeking to value [participants'] perspectives and autonomy" (Allen 2009: 407). Ethical working 
requires care, as it needs respectful communication that is based on trust and building rapport (O'Reilly 2009).

The following section describe the ethical issues we encountered as Researchers-in-Residence. Our experience highlights the inadequacy of formal ethics approaches and procedures in guiding PR and we propose a different way of thinking about ethics, through the lenses of an ethics of care. Following Guillemin and Gillam (2004), we present our findings by distinguishing between procedural ethics, or the process of seeking approval from relevant ethics committee, and ethics in practice, or the everyday ethical issues that arise in the doing of research.

\section{Two evaluations of Integrated Care in East London}

The data underpinning this paper were produced between May 2017 and July 2018, as our research team led two different participatory evaluations of integrated care in three East London boroughs. By integrated care we mean NHS organisations and local authorities working together to meet the needs of their local population, through greater coordination across hospitals, community health services and social care. The evaluations assessed implementation of two integrated care programmes; both evaluations were commissioned by the CCGs (Clinical Commissioning Groups) of the three boroughs and led by the same academic institution. The aim was to coproduce formative and summative findings and recommendations, which would inform current and future work on integrated care in the area. Two researchers (SB and $\mathrm{ML}$ ) were recruited to lead on each of these evaluation projects supervised by the same Principal Investigator (MM). In each case, the researcher was expected to embed within an operational team, work with stakeholders on the development of the research protocol and involve participants in interpreting findings and co-producing actions. Data for this paper consists of the two researchers' personal journals and field notes, including reflections from fieldwork and communication with the wider research team (Chandler and Torbert 2003).

Although there was much overlap, these were two separate studies carried out by two different researchers. The first study evaluated a programme involving all three sites and was led by SB, a social scientist and expert in PR, with no previous experience of working in clinical settings. Senior managers in two of the sites showed less interest in the research, although all three boroughs had initially commissioned it; they were all included in all aspects of research design and delivery but were less responsive and had a more traditional understanding of their involvement. The nature of the inresidence role, however, enabled SB to have access to strategic meetings and documents, as well as carrying out several informal conversations with key actors during the scoping phase.

The second study looked a different programme involving only one of the three boroughs and was led by $M L$, a health services researcher with a clinical background and previous experience of working as a Researcher-in-Residence. Senior management in this site was highly invested in both evaluations. A steering group was set up including members of the local NHS organisations and the council and met regularly to co-design the research protocols and discuss and respond to emergent findings. The steering group was a vital safe space to clarify issues and strengthen collective ownership of both studies. 
Both researchers worked closely with health and social care professionals on the ground (i.e. nurses, therapists, GPs, consultants), who were involved in the participant observations, and several among these professionals agreed to be interviewed. The researchers spent many weeks embedded in these frontline teams, who were invited to participate in workshops and meetings to interpret emergent findings at different points during the research process. A series of workshops were organised at the end of the two studies to coproduce recommendations based on the findings, which would be then presented to the steering group and other senior management meetings.

\subsection{Procedural ethics}

In order to gain REC and NHS ethics approval, the researchers went through various formal processes. Three key thematic meanings were identified relating to our experience of procedural ethics. These were coded as: "fitting an iterative process within REC requirements"; "unpacking the difference between individual consent and collective consent"; and "guaranteeing anonymity where everyone knows each other".

\subsubsection{Fitting an iterative process within REC requirements}

Institutional ethics procedures often assume that the researcher will be able to state in advance, and in some detail, who will be included in the sample, what they will be asked to do, and when and where this will occur. In a participatory study, many decisions are taken as the project progresses; things can develop quite rapidly and in unexpected ways, as the research focus is (re)negotiated with participants. Numbers of participants and their involvement can vary greatly and unpredictably over the course of the study (Guillemin and Gillam 2004). We were forced to make semi-informed guesses in terms of sample size and method choices, which we knew were likely to change substantially.

The initial scoping work raised several ethical issues. This is an integral part of PR, as the researchers try to embed themselves within the organisation and start developing relationships of trust with insider champions. This preparatory work also informs the development of the research protocol required by REC. During the scoping phase, we were already attending meetings, including operational meetings with frontline staff. This sometimes created complex situations to manage, as in the case of information on patients being shared at meetings we attended, as well as the researcher being physically within NHS premises without having yet been granted full ethics approval, or a so-called research passport. As there was prior agreement from all partner organisations to undertake the evaluation, we were expected to attend these meetings to develop understanding of the organisational culture, to identify the teams that would be involved in the project, and to collaboratively develop a rigorous protocol for ethics approval.

We often reflected on how to use the personal and field notes collected during those months of scoping work, prior to ethics approval. Although these ethnographic data have not being coded and analysed in the same way as interview data, they were not dissimilar from participatory observations that were carried out once the study "officially" started, following ethics approval. Although we always informed participants of our role, we did not have a consent form and it might have been difficult for some people to express their unwillingness to participate, as they might be attending a meeting relevant for their work. Furthermore, at these initial meetings, it was not always possible to explain in-depth the aim of the research and it might have been difficult for participants to make an informed choice. 
Another issue was the lengthy ethics approval process for health research. This can take up to six months and is particularly cumbersome when several NHS trusts and Local Authorities are involved, each with their own research governance process. It can be daunting for stakeholder organisations participating in the research that may have very different time pressures and priorities and might be used to quick-turnaround audits and service improvement evaluations carried out internally or by private consultancies. The researchers often had to negotiate between REC and NHS HRA (Health Research Authority) requirements, by which they were required to wait for approval from each of the organisations involved, and those of professionals, with partner organisations at times feeling irritated by what were perceived as "delays". Furthermore, a key objective of one of the evaluations was to understand the role of patients in care planning, their experiences of services and their involvement, or lack thereof, in service development. The evaluation team recruited a service user partner to collaborate on various aspects of the research. However, the team soon learned that neither REC nor HRA had a clear process for approving the involvement of service users in research, where they are expected to carry out research activities. ${ }^{5}$

Ethics committees emphasise protection of individuals' rights to avoid harm to people; to this end, the NHS ethics process for involving service users is more complex. However, in this case this raised ethical issues of perpetuating exclusion of patient voices. The duty to protect participants can undermine the autonomy and authority of certain groups perceived as more vulnerable, despite the intention to treat participants as equal partners and include their voices in the participatory project (Morgan et al. 2014).

\subsubsection{Informed consent: unpacking the difference between individual consent and collective consent}

The consent process generally guarantees the principle of respect for the person. However, within PR it can complicate existing relationships between participants (Boser 2006) and potentially raise risks of biased recruitment processes, therefore threatening data integrity (Löfman et al. 2004). We encountered two main ethical issues linked to informed consent. First, the signed consent form required by ethics committees does not always equate genuinely understood consent. PR entails an iterative process and participants might be asked to consent to different things at different points (Balakrishnan and Cornforth 2013). As part of our evaluation, the same members of staff were often involved in interviews, workshops, participatory observations, and as co-researchers helping design aspects of the research study, interpret findings and co-produce recommendations. Participation at different points and/ or with different hats had different implications. The requirement of one signed individual consent form comes short of what is necessary to ensure protection of participants throughout the project. Instead, we might want to develop further the concept of ongoing consent, taking a dialogic approach (Guillemim and Gillam, 2004). Renold et al. (2008: 442) reconceptualise informed consent as a "constant state of becoming, never fully realized or achieved", by adopting a critical reflexive praxis during and beyond fieldwork and embedding 'ethical talk' in everyday fieldwork relations. They recognise that "participation is a traveling concept and demands a blurring of the hierarchical binary of consent as give (active) and take (passive)". While we tried this approach informally, in line with an ethics of care, we often wondered whether it might be appropriate to formally "re-consent" research participants, depending on the changing nature of their involvement. 
The second issue we addressed concerned the concept of communal consent versus individual consent. We took part in hours of meetings at different levels of governance. At each meeting, we introduced ourselves and stated the purpose of the study. However, was there realistically an opportunity for people that did not want to take part to leave an operational meeting where they were needed as part of their job? One aspect that we might want to explore in future research is how we can ensure communal as well as individual consent. This was particularly evident when we spent time with teams of frontline staff to observe working routines. There was generally an agreement with the team lead, while consent forms were signed by staff that had agreed to be interviewed. However, other staff were also participating indirectly, without having formally consented to it, just by being in the office or clinic that day. Where staff turnover was high, newcomers might have found themselves involved in research they had not consented to, while other staff initially highly engaged left and therefore had no opportunities to input on interpretation of the findings, as agreed when they had formally consented to participate. Procedural ethics was not helpful in dealing with these issues. We relied on an ethics of care, by working as far as possible in an open and transparent manner with participants throughout the project; however, guidance on addressing these issues might have been beneficial.

\subsubsection{Guaranteeing anonymity where everyone knows each other}

RECs understand the principle of non-maleficence as protection of participant anonymity and confidentiality. In PR, however, privacy and confidentiality may be ethically problematic because of the multiple roles held by participants (Mitchell et al. 2005). Generally, anonymity and confidentiality can be difficult to guarantee in a context where people know each other. The preoccupation with anonymity might not always be well placed, as some participants may wish to be given credit and/or be named to publicise specific issues. Researchers have described feeling conflicted between the duty to maintain confidentiality and anonymity of participants and the openness of close relationships inherent to embedded roles (Brugge and Cole 2003). Because of the group nature of our work, it was not always possible to guarantee anonymity and confidentiality. Since the scope and objectives of the research had to be negotiated among partners, some within the group were inevitably aware of who was participating in the research.

Confidentiality may be situational and must often be (re)negotiated. The thick descriptions that are often the measure of good quality qualitative research can unwittingly reveal people's identity. In one case, the researcher evaluated a pilot of a service that had the potential to foster more patient-centred and integrated care. As the team was small, the risk of inadvertent disclosure was high. Moreover, the evaluation findings suggested challenging team dynamics together with a strained relationship between the team and senior management. This presented a set of ethical challenges for the researcher, including selective reporting of findings, whereby the latter might be regarded itself as an ethical issue. In another instance, issues of poor dialogue across teams and complaints about management styles emerged as key findings that needed addressing to improve integrated working. The risk was to exacerbate conflicts and a blame game between individuals, as, even if no one was named, it was clear from the description of the issue who the managers were. While it was clearly important to deal with this information, it also posed important dilemmas for the researcher. We tried to manage these situations by following an ethics of care approach and creating safe spaces of open dialogue. It was a 
difficult balancing act, as we tried to reassure participants, while also maintaining intellectual honesty with regard to the findings. We emphasised the focus on learning rather than blaming and ensured there was buy-in for this approach from senior management.

However, the issue of anonymity and confidentiality takes on a new dimension in PR and this is not reflected in a REC process. One thing that we could have done with hindsight is to raise issues of confidentiality and anonymity in consensus-building discussions early in the project, ensuring all research partners adhered to the agreed standards, enabling both researchers and participants to have greater awareness of communal, as well as individual risks and benefits (Quigley 2006).

\subsection{Ethics in practice}

The everyday ethical issues that arise when doing research punctuate the daily life of embedded researchers who continuously negotiate complex social situations and power dynamics and face multiple choices and their ethical implications, while guaranteeing transparency about such choices (Reason 2006). Those "ethically important moments" where decisions have to be made quickly can have important implications for participants and researchers (Guillemin and Gillam 2004). We identified four key thematic meanings relating to our experience of everyday ethics: "managing power dynamics on the ground"; "the importance of rapport for ethical research"; "challenging dominant narratives through mobilising knowledge"; "reflecting different perspectives in data interpretation" (see also Nyman et al. 2016). These themes reflect general qualitative research tensions but raise novel ethical dilemmas for researchers-in-residence.

\subsubsection{Managing power dynamics on the ground}

At the start of the project, we immediately faced several challenges as we tried to understand the context. We recognised that engaging complex and hierarchical organisations would be difficult but it proved to be even more challenging than we had assumed. Although there is increasing interest in formative and participatory evaluation, culture change within health organisations takes time. Instead, we found ourselves having to redevelop some of the focus and methodological approaches; at times, it felt as if we were carrying out the research on our own with limited engagement from some senior managers. The researcher and participants come to the project with their own preconceived ideas, their own experiences, and world-views; this leads to a range of differing assumptions and sometimes misunderstandings. Since several organisations were involved in both evaluations, it was often difficult to manage different pressures and accommodate different priorities. PR often addresses issues around "giving voice", but a "recurring issue for researchers is that of whose voice is being spoken and, simultaneously, whose voice is being heard" (Mannay 2016: 6), whereby some voices can also be inadvertently excluded (Alexandra 2015; Lomax 2018). We often risked paying too much attention to those actors (generally from community health services) that appeared to be more engaged with the evaluation. This could potentially bias findings as the voice and interests of other actors from acute or social care played a more limited role.

PR is imbued with power dynamics, and often power asymmetries (Mannay 2015). One of the researchers worked very closely with one senior manager with a high degree of influence within the wider partnership. Although this manager acted as a champion of the evaluation, at several points the 
researcher felt this person had too much influence on key decisions, crowding out input from the wider group. The researcher felt at times under pressure to support dominant discourses; in some cases, perceived alignment of the researchers with some senior figures within organisations might have affected the engagement of frontline professionals. Decoding these power dynamics is one major challenge for the researcher-in- residence, who might feel overwhelmed in the "swampy lowlands" of messy real life practice (Schon 1984). By understanding and acknowledging the different meanings that actors ascribed to the evaluation we were able to address some of these issues. The evaluation was perceived by some as a way to validate the outcomes of the programme rather than generating new insights to improve practice. Embedding safe spaces for dialogue throughout fieldwork helped the team reinforce their role as critical friends holding up a mirror and minimise conflict.

\subsubsection{The importance of rapport for ethical research}

The importance of rapport for the quality and ethics of research is a recurrent theme in ethnographic research (O'Reilly 2009; Iphofen 2020). The participatory approach entails being open to co-decisions with participants, but trust-building is an ongoing process and it was not always easy to ensure there was no perceived hierarchy between the researchers and the participants. Feminist researchers (e.g. Finch, 1984; Oakley, 1981) have long attempted to redress the power imbalances between researchers and researched by replacing the hierarchical stance of the 'neutral researcher' of conventional approaches with more intimate, 'authentic' and 'sisterly' relations with those studied (Patai, 1991; Reinharz, 1983). However, the closeness of researcher and researched may mask 'a deeper, more dangerous form of exploitation' (Stacey, 1991: 113) and create opportunities for manipulation, as participants disclose private information to researchers they may come to consider as friends (Wolf, 1996). Inequalities must therefore be clearly acknowledged and researchers need to recognise that reciprocal relationships at times may be disingenuous, particularly since the researchers eventually will leave the field (Reinharz 1992; O'Reilly 2009). Leaving can be problematic in itself in much qualitative and ethnographic research, depending on the kinds of relationship that have been built. Whereas in PR the participants are not left anxious to know what the researcher will write about when s/he leaves, as the findings are coproduced, there might be similar worries about possible implications of the research for those who stay. As SB and ML worked closely with frontline staff they were very aware of these issues.

Both researchers continuously sense-checked, by discussing and reflecting on emerging findings with participants and trying to make sense with them of different viewpoints. However, this also meant being very open to staff criticising the findings, as they were often understandably protective of their service. In a fragmented context such as today's NHS, where the rhetoric on collaboration and holistic care clashes against the reality of organisations competing for contracts, it was sometimes challenging to move away from a blaming culture along organisational allegiances and towards coproducing learning for all. While navigating these challenges was no easy task, applying an ethics of care helped emphasise the importance of relationships based on mutual understanding and respect for difference.

\subsubsection{Challenging dominant narratives through mobilising new knowledge}

As Researchers-in-Residence, we often had to manage the risk of being influenced by potentially conflicting worldviews. On the one hand, at senior-level meetings we were fed the prevailing discourse 
on efficiency saving and the rhetoric on collaboration and holistic, patient-centred care. On the other hand, we shared the emotional and psychosocial stress of clinicians and other professionals on the ground experiencing increased organisational fragmentation and a constant lack of human and financial resources that propelled them towards task-orientated roles, making their organisation's ambition to deliver holistic care near impossible. Trading a detached, distant, and objective stance for an intimate, close, and equitable position raises several new ethical issues, as boundaries can be messy. Reflective sessions helped us ensure we continued to play a constructive critical friend role. However, a huge challenge was to present the findings in a way that both acknowledged the issues experienced by frontline staff and yet focused on positive lessons and steps forward, ensuring that the findings did not reflect badly on individual organisations.

Organisational politics implies balancing the requirements for the success and quality of the research, participant organisations' need to preserve their reputation and protect their work, and the Researchers-in-Residence's need to maintain credibility as effective drivers of change (see also Coghlan and Brannick 2010). In one instance, emergent findings began to shed some new light on the working of one organisation and its (not always positive) impact on partners; these findings challenged the dominant rhetoric within the organisation and how it perceived itself (as being innovative and efficient). The risk was to compromise relationships with key actors from the organisation, who had been strong champions of the evaluation. Once again, the researcher worked to ensure the focus was on developing learning and stronger partnerships. Dialogue was at times challenging with some senior management keen to use the evaluation as a means of showcasing their work. It required continuously emphasising the nature of the in-residence approach as holding up a mirror to mobilise new knowledge, making a case for the importance of reporting the 'truth' as the participants saw it to enable senior management to understand the challenges facing frontline staff. To be an agent of change, a colleague, and a researcher often risks role conflict (Holian and Coghlan 2013; Nyman et al. 2016); caring to listen to participants' voices and viewpoints was as challenging as it was rewarding.

\subsubsection{Reflecting different perspectives in data interpretation}

Data ownership and interpretation of findings are among the most problematic areas of PR ethics. Participants can be stigmatised when information is not handled sensitively and might cause damage to the organisation's reputation and relationships (Quigley 2006). Participants can also feel exploited, particularly in contexts such as health and social care where a plethora of audits, Quality Improvement initiatives, and evaluations are routinely carried out, with limited follow up on the findings or feedback to participants. In line with the participatory ethos, we facilitated opportunities to co-interpret emergent findings. This was generally constructive, but we experienced some challenging situations. In one case, some participants felt threatened by findings that highlighted duplication of roles and feared the report could imply that their team should be reconfigured. This added stress to the relationship with this team, which had really engaged with the research but now felt stigmatised. By acknowledging these feelings, the researcher was able to reassure the team lead that the report's purpose was to help improve coordination rather than assess performance of individual services. It was agreed the final report would be shared with the team for further feedback before being circulated within the wider organisation. In another instance, staff felt their role was not reflected properly in the reports; we went 
back together to the data and worked towards a more accurate representation of the roles. In each case, we relied on transparency in data analysis and rapport building.

Table 1 summarises the main ethical challenges raised by the in-residence model, and PR more broadly, and strategies to address these based on an ethics of care.

Table 1. Ethics of principle v. ethics of care in PR

\begin{tabular}{|c|c|c|c|}
\hline \multicolumn{2}{|c|}{ Ethical Participatory Research } & \multirow{2}{*}{$\begin{array}{l}\text { Issues raised by } \\
\text { Ethics of principle } \\
\text { The number of } \\
\text { participants and the way } \\
\text { they are involved can } \\
\text { vary greatly over the } \\
\text { course of the study and } \\
\text { may be hard to predict as } \\
\text { required by RECs. }\end{array}$} & \multirow{2}{*}{$\begin{array}{l}\text { Answers offered } \\
\text { by Ethics of care } \\
\text { Acknowledges that in } \\
\text { a participatory study, } \\
\text { things can develop in } \\
\text { unexpected ways }\end{array}$} \\
\hline $\begin{array}{l}\text { Procedural Ethics } \\
\text { Institutional ethics } \\
\text { procedures }\end{array}$ & $\begin{array}{l}\text { Predictability of } \\
\text { process and } \\
\text { outcome }\end{array}$ & & \\
\hline & Informed consent & $\begin{array}{l}\text { One signed consent form } \\
\text { does not always equate } \\
\text { informed consent. }\end{array}$ & $\begin{array}{l}\text { Reflective approach to } \\
\text { issues of ongoing/ } \\
\text { communal consent }\end{array}$ \\
\hline & $\begin{array}{l}\text { Anonymity and } \\
\text { confidentiality }\end{array}$ & $\begin{array}{l}\text { Can be difficult to } \\
\text { guarantee in a context } \\
\text { where people know each } \\
\text { other well }\end{array}$ & $\begin{array}{l}\text { Safe spaces } \\
\text { Consensus-building } \\
\text { discussions early in } \\
\text { the project, enabling } \\
\text { both researchers and } \\
\text { participants to have } \\
\text { greater awareness of } \\
\text { communal, as well as } \\
\text { individual risks and } \\
\text { benefits }\end{array}$ \\
\hline \multirow[t]{3}{*}{$\begin{array}{l}\text { Ethics in practice } \\
\text { Everyday ethical issues } \\
\text { that arise when doing } \\
\text { research }\end{array}$} & Power dynamics & $\begin{array}{l}\text { Role of "outside expert" } \\
\text { does not fit the } \\
\text { democratic ethos of PR. }\end{array}$ & $\begin{array}{l}\text { Understanding of } \\
\text { different meanings } \\
\text { that actors ascribed to } \\
\text { the PR } \\
\text { Emphasis on } \\
\text { developing } \\
\text { relationships of trust/ } \\
\text { rapport }\end{array}$ \\
\hline & $\begin{array}{l}\text { Data ownership } \\
\text { and interpretation }\end{array}$ & $\begin{array}{l}\text { Participants can feel } \\
\text { exploited and/ or } \\
\text { stigmatised. }\end{array}$ & $\begin{array}{l}\text { Transparency in data } \\
\text { analysis, rapport- } \\
\text { building, } \\
\text { opportunities for } \\
\text { feedback }\end{array}$ \\
\hline & $\begin{array}{l}\text { Blurred boundaries } \\
\text { between }\end{array}$ & $\begin{array}{l}\text { Challenge of keeping } \\
\text { critical distance }\end{array}$ & Reflective approach \\
\hline
\end{tabular}




\begin{tabular}{|l|l|l|l|}
\hline & $\begin{array}{l}\text { researcher(s) and } \\
\text { participants }\end{array}$ & $\begin{array}{l}\text { Holding up a mirror to } \\
\text { mobilise new } \\
\text { knowledge }\end{array}$ \\
\hline
\end{tabular}

\section{Conclusion}

This paper offered a critical reflection on how the four principles of respect for autonomy, beneficence, non-maleficence, and justice often have different implications for researchers engaged in PR, particularly when examined in terms of the contrasting issues raised by procedural ethics and ethics in practice. PR offers real opportunities for democratising the research process by including different voices, interests, and expertise. It also problematises traditional ethical approaches, processes and issues, while raising new questions. In line with other literature on PR and ethnography (Allen 2009), we found that the REC process offered no guidance on many aspects, forcing researchers to jump through hoops to fit an iterative process into requirements developed with a sequential linear process in mind. Furthermore, the REC process did not help us to reflect on crucial ethical implications of being embedded, in terms of protecting both participants and researchers. In fact, unintentional harm could arise as a result of researchers struggling to apply requirements of misaligned ethical models (Flicker et al., 2007). Thus, PR requires a shift in the ethical review process "from operating prospectively to adapting to evolving qualitative research methods that require staggered ethical review in response to emergent issues" (Wilson et al. 2018:192). In this respect, an ethics of care was more appropriate in supporting the researchers as they tried to enable all participants to make genuine choices at different points in the process without negative repercussions. The principle of respect for persons may be a less demanding ethical precept than is the ethics of care, whereby our responsibilities as caring researchers are much greater (Preissle 2012). What this ethics of relationship adds to the ethics of principle is a complementary framework to address some of the challenges emerging from the practice of PR.

The messy nature of PR means that it is often a difficult journey; in the real workplace, priorities change and the unexpected often disrupts any planned research actions. Options for data collection and analysis need to be flexible and responsive to feedback. We constantly had to think reflectively and consider implications and repercussions at each point, in order to guarantee the quality of our findings and nurture relationships of trust with the participants: Is what happening relevant to the evaluation? How can it be captured? How can we include this piece of information without being seen to criticise an individual or an organisation? The concepts of reflexivity and reciprocity were crucial to help us examine critically motivation for initiating the research, intentions and expectations, and to address questions about who may benefit and who may have to carry a burden. Narrow procedural ethics arrangements can prevent harm from research (though this is no easy matter in a complex situation); however, they do little towards helping to promote the good in PR relationships. An ethics of care allowed us to judge the quality of our researcher roles and human interactions within the research process. However, the asymmetries arising from the different interests of researchers, participants, and researcher-participants are inevitable and require acknowledgement. One of the main ethical challenges was to ensure flexibility about what we could include and exclude in the report without affirming dominant discourses. Power, knowledge, consciousness and action are intertwined; what may appear to be consensus about 
issues within an organisation may be simply replicating the dominant discourse (Gaventa and Cornwall 2007).

This paper has offered several examples of ethical challenges routinely faced by participatory and embedded researchers and suggested a framework to examine these different issues and their implications for both the quality of the research and the wellbeing of participants and researchers alike. Further research should focus on how to support Researchers-in-Residence, and participatory researchers generally, particularly within healthcare settings, where PR is often at odds with the embedded positivist approach. New research should continue to raise awareness of everyday ethical challenges and strategies to address these but also promote greater understanding of PR and methodological innovations among institutional ethics committees, to help them develop more appropriate ethics approval processes. These should integrate an ethics of care with the traditional ethics of principle.

Word count excluding the table: 8909

\section{REFERENCES}

Alexandra, D. (2015). Are we listening yet? Participatory knowledge production through media practice: Encounters of political listening. In A. Gubrium, K. Harper, \& M. Otanez (Eds.), Participatory visual and digital research in action (pp. 41-56). Walnut Creek, CA: Left Coast Press.

Allen, L. (2009). Caught in the act: Ethics committee review and researching the sexual culture of schools. Qualitative Research, 9(4), 395-410.

Balakrishnan, Vishalache, and Sue Cornforth. 2013. "Using Working Agreements in Participatory Action Research: Working through Moral Problems with Malaysian Students." Educational Action Research.

Banks, Sarah et al. 2013. "Everyday Ethics in Community-Based PR." Contemporary Social Science. Beauchamp and Childress (2001) Principles Biomedical Ethics, OUP, 5th edition.

Bergold, Jarg, and Thomas Stefan. 2012. "PR Methods : A Methodological Approach in Motion." Forum: Qualitative Social Research.

Boivin, A et al. 2014. "Involving Patients in Setting Priorities for Healthcare Improvement: A Cluster Randomized Trial." Implement Sci.

Boser, Susan. 2006. "Ethics and Power in Community-Campus Partnerships for Research." Action Research.

Brugge, D, and A Cole. 2003. "A Case Study of Community-Based PR Ethics: The Healthy Public Housing Initiative." Science and Engineering Ethics.

Campbell-Page, Ruth M., and Mary Shaw-Ridley. 2013. "Managing Ethical Dilemmas in CommunityBased PR With Vulnerable Populations." Health Promotion Practice.

Chandler, Dawn, and Bill Torbert. 2003. "Transforming Inquiry and Action: Interweaving 27 Flavors of Action Research." Action Research.

Coghlan, David, and Teresa Brannick. 2010. Doing Action Research in Your Own Organization Doing Action Research in Your Own Organization.

Dewey, J. ([1930]1984), 'What I believe', in Boydston, J. A. (ed.) (1984), John Dewey: The later works, 1925-1953, Vol. 5, Carbondale and Edwardsville: Southern Illinois University Press, pp. 267-278.

Edwards, V. (2019) http://www.exchangewales.org/single-post/2019/05/15/How-might-we-work-moreEthically-with-Children-and-Young-People-The-\%E2\%80\%98Case-of-Ethics\%E2\%80\%99

Fischer, Frank. 2000. "Citizens, Experts, and the Environment: The Politics of Local Knowledge." 
Contemporary Sociology.

Flicker, Sarah et al. 2007. "Ethical Dilemmas in Community-Based PR: Recommendations for Institutional Review Boards." Journal of Urban Health.

Gaventa, John, and Andrea Cornwall. 2007. "Power and Knowledge." The Sage handbook of action research: Participative inquiry and practice.

Genat, Bill. 2009. "Building Emergent Situated Knowledges in Participatory Action Research." Action Research.

Gilligan, Carol. 1982. "Psychological Theory and Women's Development." In In a Different Voice,.

Githens, Rod P. 2015. "Critical Action Research in Human Resource Development." Human Resource Development Review.

Guillemin, Marilys, and Lynn Gillam. 2004. “Ethics, Reflexivity, and 'Ethically Important Moments' in Research." Qualitative Inquiry.

Hampshire, S. 1978. Public and Private Morality. Cambridge University Press.

Held, Virginia. 1987. "Feminism and Moral Theory." Women and Moral Theory.

Holian, Rosalie, and David Coghlan. 2013. "Ethical Issues and Role Duality in Insider Action Research: Challenges for Action Research Degree Programmes." Systemic Practice and Action Research.

Holmes, Bev J. et al. 2017. "Mobilising Knowledge in Complex Health Systems: A Call to Action." Evidence and Policy.

Iphofen, R. ed. (2020) Handbook of research ethics and scientific integrity. Cham: Springer

Latchem-Hastings, G. (2018). The emotion of 'doing ethics' in healthcare research: A researcher's reflexive account. In T. Loughran \& D. Mannay (Eds.), Emotion and the researcher: Sites, subjectivities and relationships (Vol. 16). Studies in Qualitative Methodology (pp. 213-228). Bingley: Emerald.

Lomax, H. (2015). Seen and heard? Ethics and agency in participatory visual research with children, young people and families. Families, Relationships and Societies, 4(3), 493-502.

Loughran, T. and Mannay, D. 2018. Introduction: Why emotion matters. In: Loughran, T. and Mannay, D. eds. Emotion and the researcher: sites, subjectivities, and relationships., Vol. 16. Studies in Qualitative Methodology Bingley: Emerald, pp. 1-18.

Lewin, Kurt. 1946. "Action Research and Minority Problems." Journal of Social Issues.

Löfman, Päivi, Marjaana Pelkonen, and Anna-Maija Pietilä. 2004. "Ethical Issues in Participatory Action Research." Scandinavian journal of caring sciences.

Macintosh, Robert, Marc Bonnet, Judi Marshall, and Peter Reason. 2007. "Quality in Research as 'Taking an Attitude of Inquiry.'" Management Research News.

Maiter, S., L. Simich, N. Jacobson, and J. Wise. 2008. "Reciprocity: An Ethic for Community-Based Participatory Action Research." Action Research.

Mannay, D. 2015. Visual Narrative and Creative research methods: Application, reflection and ethics. London: Routledge.

Mannay, D. (2016). Visual, narrative and creative research methods: Application, reflection and ethics. Abingdon: Routledge.

Mannay, D. Staples, E. and Edwards V. 2017. Visual methodologies, sand and psychoanalysis: employing creative participatory techniques to explore the educational experiences of mature students and children in care. Visual Studies. 32:4, pp.345-358.

Mannay, D. et al. (2018): Enabling talk and reframing messages: working creatively with care experienced children and young people to recount and re-represent their everyday experiences, Child Care in Practice, DOI: 10.1080/13575279.2018.1521375

Marshall, Martin et al. 2014. "Moving Improvement Research Closer to Practice: The Researcher-inResidence Model." BMJ Quality and Safety.

Marshall, Martin N. 2014. "Bridging the Ivory Towers and the Swampy Lowlands; Increasing the Impact 
of Health Services Research on Quality Improvement." International Journal for Quality in Health Care.

Maurer, Martin, and Rod P. Githens. 2010. "Toward a Reframing of Action Research for Human Resource and Organization Development: Moving beyond Problem Solving and toward Dialogue." Action Research.

McNiff, Jean, and Jack Whitehead. 2011. Action Research All You Need to Know about Action Research.

Minkler, Meredith, and Nina Wallerstein. 2011. "Introduction to Community-Based PR: From Processes to Outcomes." In Community-Based PR for Health: From Process to Outcomes,.

Mitchell, Terry Leigh, Emerance Baker, and Lisa Castro. 2005. "Community-Building versus CareerBuilding Research: The Challenges, Risks, and Responsibilities of Conducting Research with Aboriginal and Native American Communities." Journal of Cancer Education.

Moody-Adams, Michele-M. 1997. "Fieldwork in Familiar Places: Morality, Culture, and Philosophy." Philosophy and Phenomenological Research.

Morgan, Michelle F., Monica Cuskelly, and Karen B. Moni. 2014. "Unanticipated Ethical Issues in a PR Project with Individuals with Intellectual Disability." Disability \& Society.

Noddings, Nel. (1984) Caring: A Feminine Approach to Ethics and Moral Education. University of California Press

------1988. "An Ethic of Caring and Its Implications for Instructional Arrangements Author(s An Ethic of Caring and Its Implications for Instructional Arrangements." Nel Noddings Source: American Journal of Education American Journal of Education This.

- - . 2015. "Care Ethics and 'Caring' Organizations." In Care Ethics and Political Theory,.

Nyman, Viola, Marie Berg, Soo Downe, and Terese Bondas. 2016. "Insider Action Research as an Approach and a Method - Exploring Institutional Encounters from within a Birthing Context." Action Research.

O’Reilly, K. 2009. Key concepts in Ethnography. London: Sage Preissle, Judith, and Yuri Han. 2012. "Feminist Research Ethics." In Handbook of Feminist Research. Theory and Praxis,.

Quigley, Dianne. 2006. "Perspective: A Review of Improved Ethical Practices in Environmental and Public Health Research: Case Examples From Native Communities." Health Education \& Behavior.

Reason, Peter. 2006. "Choice and Quality in Action Research Practice." Journal of Management Inquiry. Reason, Peter, and Hilary Bradbury. 2006. "Handbook of Action Research." Participative Inquiry and Practice London.

Renold et al. 2008. 'Becoming Participant': problematizing 'informed consent' in PR with young people in care. Qualitative Social Work. 7:4, pp.427-447.

Schon, Donald A. 1984. "The Reflective Practitioner." Harvard Business Review.

Staples, E., Roberts, L., Lyttleton-Smith, J., Hallett, S., \& CASCADE Voices. (2019). Enabling care experienced young people's participation in research: CASCADE voices. In D. Mannay, A. Rees, \& L. Roberts (Eds), Children and young people 'looked after'? Education, intervention and the everyday culture of care in Wales (pp. 196-209). Cardiff: University of Wales Press.

Vindrola-Padros, Cecilia et al. 2018. "Addressing the Challenges of Knowledge Co-Production in Quality Improvement: Learning from the Implementation of the Researcher-in-Residence Model." BMJ Quality and Safety.

Vindrola-Padros, Cecilia, Tom Pape, Martin Utley, and Naomi J. Fulop. 2017. "The Role of Embedded Research in Quality Improvement: A Narrative Review." BMJ Quality and Safety.

Wilson, Elena, Amanda Kenny, and Virginia Dickson-Swift. 2018. "Ethical Challenges in Community-Based PR: A Scoping Review." Qualitative Health Research. 
World Medical Association. (2001). World Medical Association Declaration of Helsinki. Ethical principles for medical research involving human subjects. Bulletin of the World Health Organization, 79 (4), 373 - 374. World Health Organization.

\footnotetext{
${ }^{1}$ Kurt Lewin's planned approach to change involves a three-stage process: unfreezing current behaviour; moving to the new behaviour; and refreezing the new behaviour.

${ }^{2}$ The critical grounding of Paulo Freire's (1970) emancipatory focus underpins the PAR approach. Freire used the concept of praxis to mean reflection and action on the world to transform it.

${ }^{3}$ One might argue that PR is heavily ethically implicated from the start, as it might not be clear who defines what 'good' or 'desirable' change might be and who is accountable for the work, and to whom. Whereas the rationale of PR is to democratise the research process by including and recognising different interests and by opening it up to ensure greater transparency and foster group ownership, inevitably power dynamics will still exist but within a non-hierarchical context might be less visible and harder to recognise. This problematises accountability in PR. ${ }^{4}$ http://www.exchangewales.org/single-post/2019/05/15/How-might-we-work-more-Ethically-with-Children-andYoung-People-The-

${ }^{5}$ It took 10 months to gain approval for the service user-researcher to carry out interviews with other patients. That a study needs to build in 10 months into a project for research ethics and governance approvals might be indication of a flawed process.
} 